\title{
Agressores de pessoas idosas: interpretando suas vivências
}

\author{
Aggressors of older people: interpreting their experiences
}

\author{
Murilo Santos Oliveira' $\mathbb{I D}$ \\ Miriam Fernanda Sanches Alarcon² ${ }^{2}$ \\ Fernanda Moerbeck Cardoso Mazzetto ${ }^{3}$ (D) \\ Maria José Sanches Marin' $\mathbb{I D}$
}

\section{Resumo}

Objetivo: Interpretar a vivência dos denunciados de agressão à pessoa idosa no que se refere ao contexto de violência e dinâmica das relações. Métodos: Trata-se de um estudo qualitativo, realizado a partir de entrevistas presenciais com 16 participantes denunciados por agressões à pessoa idosa, entre março a dezembro de 2019. As entrevistas foram realizadas na Delegacia de Defesa da Mulher em uma cidade do interior Paulista, SP, Brasil e, em alguns casos, no próprio domicílio do denunciado. Os dados foram analisados por meio da técnica de análise temática. Resultados: reconheceu-se a existência de dependência mútua, seja financeira ou de cuidados e que, quanto aos agressores, esses negam, justificam e minimizam a agressão, atribuindo o ato ao comportamento do idoso ou mesmo ao passado em que sofria agressão pelos mesmos. Os denunciados reconhecem que necessitam de ajuda, ao considerar seus problemas emocionais, o uso

Palavras-chave: Violência. Envelhecimento. Saúde do Idoso. de drogas psicoativas e o exercício do estenuante papel de cuidador. Ainda admitem possuir remorso pelo ocorrido, manifestando autonegligência e desejo de apagar o fato. Conclusão: O estudo evidenciou que o denunciado apresenta necessidades e vulnerabilidades próprias, em relações familiares de difícil manejo e que, em muitos casos, se manterá, mesmo com a ocorrência. Nestas situações, é preciso que haja uma escuta ampliada do envolvidos, em um trabalho intersectorial.

\footnotetext{
Faculdade de Medicina de Marília (FAMEMA), Programa de Pós-Graduação Mestrado Acadêmico em Saúde e Envelhecimento. Marília, SP, Brasil.

2 Universidade Estadual do Norte do Paraná, Departamento de Enfermagem. Bandeirantes, PR, Brasil.

3 Faculdade de Medicina de Marília (FAMEMA), Departamento de Enfermagem. Marília, SP, Brasil.
}

Financiamento da pesquisa: Fundação de Amparo à pesquisa do Estado de São Paulo (FAPESP). $\mathrm{N}^{\circ}$ do processo: 2017/17562-2.

Os autores declaram não haver conflito na concepção deste trabalho. 


\section{Abstract}

Objective: To interpret the experience of those accused of assaulting the elderly in relation to the context of violence, feelings and the dynamic emotions involved. Methods: This is a qualitative study, carried out based on face-to-face interviews with 16 participants who were reported for assaulting the elderly, from March to December 2019. The interviews were conducted at the women's police station in a city in the interior of the state of São Paulo, Brazil, and in some cases, at the defendant's own home. The data were analyzed using the thematic analysis technique. Results: The existence of mutual dependence, whether financial or care, was recognized. The aggressors deny, justify and minimize the aggression, attributing the act to the behavior of the elderly or even to the past in which they suffered aggression by them. The accused recognize that they need help and have emotional problems, then using psychoactive drugs to suppress their role as caregiver. Furthermore, they admit to having remorse for what happened, manifesting self-neglect and desire to erase the fact. Conclusion: The study showed that the defendants have complex health needs that deserve a close look from health professionals and actions focused on the relationship between the accused and the victim, mainly when considering that it will perpetuate itself after the occurrence.

\section{INTRODUÇÃO}

O crescimento da população idosa, antes um processo verificado apenas em países desenvolvidos, constitui-se atualmente em um desafio para todo o mundo. À medida que a sociedade envelhece, crescem também os desafios para cuidar de uma população que pode acumular uma série de limitações físicas e cognitivas decorrentes desse processo ${ }^{1}$.

O processo de envelhecimento pode reduzir a capacidade funcional e consequentemente a autonomia da pessoa idosa, que pode passar a depender de outras pessoas. Segundo a Constituição Federal, é dever do Estado e da Família a garantia do bem-estar e do exercício da cidadania de indivíduos idosos, estabelecendo reponsabilidade aos filhos maiores em amparar os pais na velhice ${ }^{2,3}$. No entanto, embora o cuidado familiar ainda seja predominante, as transformações pós-modernidade, como as modificações na composição, insuficiência familiar e o enfraquecimento dos laços e vínculos intergeracionais, comprometem a oferta de cuidado ao idoso necessitado ${ }^{4}$.

Quando o vínculo familiar está prejudicado, possivelmente a família deixa de fornecer segurança, companhia e ajuda ao seu idoso, o que pode ampliar os riscos a sua saúde e à própria sobrevivência ${ }^{5}$. Além disso, em muitas situações, a família apresenta-se insuficiente, como por exemplo: contextos em que a pessoa que deveria cuidar do idoso encontra-se com problemas de saúde física e/ou mental ou é usuária de álcool ou drogas. Essa é a realidade vivida por diversos idosos em seu contexto familiar, o que gera maior complexidade à resolução do problema ${ }^{6}$.

Assim, dentre os problemas enfrentados por essa população, merece destaque a violência que, apesar de considerada grave problema de saúde pública, ainda é camuflada na sociedade ${ }^{7}$.

A violência contra idosos é um fenômeno internacionalmente reconhecido e também conhecido por uma escassez de dados. Dentre os motivos relacionados à subnotificação desses casos, podem ser considerados: o conluio e segredo familiar, o receio da vítima em quebrar vínculos e as imposições provocadas pelos agressores que frequentemente são os próprios cuidadores; além das limitações cognitivas e físicas dos agredidos ${ }^{8,9}$.

Segundo informações do Sistema de Vigilância de Violências e Acidentes (VIVA), no ano de 2014, foram notificados 12.297 casos de violência contra a pessoa idosa no Brasil (sendo 43,7\% de repetição). Dentre os tipos de abusos praticados, foram encontrados: violência física/sexual (64\%), psicológica/moral (28,2\%), negligência/abandono $(26,4 \%)$ e financeira $(7,4 \%)$, sendo, em sua maioria $(28,4 \%)$ praticadas por seus filhos ${ }^{10}$.
Keywords: Violence. Aging. Health of the Elderly. 
Na verificação da violência contra idosos a partir de boletins de ocorrências (BOs) registrados em três municípios de diferentes regiões do Brasil, no período de 2009 a 2013, constatou-se predomínio da faixa etária de 60 a 69 anos, do sexo feminino e de casados, sendo os agressores predominantemente indivíduos entre 30 e 49 anos do sexo masculino ${ }^{11}$.

Em nossa realidade cabe essencialmente à família prestar cuidados aos idosos, visto que são limitados os recursos públicos voltados a essa parcela da população. Quando se trata da violência contra o idoso, tem-se observado que ela ocorre principalmente no domicílio e os agressores são os próprios familiares. Uma análise de ocorrências policiais em um município paulista de médio porte, entre os anos de 2008 e 2012, verificou que de um total de 572 casos, a maior parte dos agressores eram homens $(69,20 \%)$, brancos $(56,50 \%)$, faixa etária $31-40 \operatorname{anos}(14,20 \%)$ e sem informação quanto à ocupação $(50,70 \%)$, sendo os filhos principais agressores $(25,30 \%)^{7}$.

Diante do exposto, motivado pela complexidade das situações de violência e das dificuldades dos diferentes setores em enfrentar esse problema, especialmente porque em muitos casos os denunciados e agredidos continuarão dividindo os mesmos espaços; além da escassez de estudos que tenham um olhar para o agressor, este estudo objetivou interpretar a vivência dos denunciados de agressão à pessoa idosa no que se refere ao contexto de violência e dinâmica das relações.

\section{MÉTODO}

Trata-se de um estudo qualitativo, realizado a partir de entrevistas com denunciados de agressão à pessoa idosa, tendo como forma de tratamento dos dados a análise temática, por ser considerada como ferramenta utilizada em diferentes métodos, dada à sua flexibilidade ${ }^{12}$.

A pesquisa foi realizada em um Município de médio porte do interior de São Paulo, SP, Brasil, com uma população de 216.745 habitantes, da qual $13,6 \%$ são idosos ${ }^{13}$. Teve como cenário para a coleta de dados a Delegacia de Defesa da Mulher (DDM), da Central de Polícia Judiciária da Polícia Civil.
A seleção dos denunciados deu-se pela indicação da delegada responsável pelo serviço. No momento em que a delegacia recebia a ocorrência relacionada a violência contra o idoso, os pesquisadores eram acionados para proceder a entrevista. Foram incluídos no estudo denunciados de agressão a idosos que residiam no Município e que tinham condições de comunicação para fornecer as informações necessárias. Foram excluídos aqueles que representaram risco de agressão ou capacidade cognitiva comprometida.

A coleta de dados ocorreu no período de março a dezembro de 2019, nas dependências da DDM e, em alguns casos, nas residências dos denunciados em local e horários previamente pactuados por telefone. As entrevistas foram realizadas por dois pesquisadores treinados, sendo um psiquiatra que era o pesquisador principal e conduziu as entrevistas. Houve um encontro com cada denunciado de agressão com duração entre 16 a 81 minutos, com média de 39 minutos para realização das entrevistas, as quais foram gravadas e posteriormente transcritas na íntegra.

A coleta de dados foi realizada por meio de entrevistas semiestruturadas presenciais com os denunciados de agressão a idosos. Utilizou-se como guia um roteiro contendo dados de caracterização sociodemográfica (idade, sexo, escolaridade, grau de parentesco com o idoso, dependência financeira, se mora com o idoso e se é o cuidador); dados sobre o uso de alcool ou drogas ilícitas e presença de transtorno mental. A entrevista foi composta por 7 perguntas elaboradas de acordo com o objetivo: 1- Fale sobre a sua relação com o idoso 2- A que você atribui o fato de ter agredido o idoso 3-Como você está se sentindo em relação ao ocorrido? 4- Fale sobre quais aspectos o idoso depende de você 5 - Fale sobre a sua dependencia em relação ao idoso 6- Fale como você cuida da sua saúde.

Ao final das entrevistas era realizado acolhimento e escuta de algo que o entrevistado tivesse necessidade de expor, finalizando com apontamentos, orientações e direcionamentos de cuidados, conforme as necessidades apresentadas.

As entrevistas foram encerradas no momento em que houve a saturação dos dados, o que, segundo Minayo $^{14}$, pode ser entendida como o momento da 
pesquisa no qual a coleta de novos dados não traria mais esclarecimentos para o objeto estudado.

Segundo Braun e Clarke ${ }^{12}$ a trajetória dessa análise é apresentada em seis fases, não se tratando de um processo linear em que uma fase precede a outra, sendo necessário aplicar a flexibilidade e ser exaustivo na interação com os dados, para que se possa gerar percepções ricas e complexas.

$\mathrm{Na}$ proposição das fases a serem seguidas, inicialmente coloca-se a familiaridade com os dados, que compreende a imersão por meio de leituras repetidas dos dados de forma a se aproximar da profundidade e amplitude do conteúdo ${ }^{12}$.

A segunda fase envolve a produção de códigos iniciais a partir dos dados, sendo que estes representam um conteúdo semântico ou latente que se referem ao segmento ou elemento mais básico do dado ${ }^{12}$.

A fase três, que se refere à procura por temas, a qual desenvolvida a partir da lista de códigos e envolve a triagem dos diferentes códigos em temas potenciais $^{12}$.

$\mathrm{Na}$ fase quatro, foi momento de revisitar os temas, o que envolve o seu refinamento, leva em consideração os critérios de homogeneidade interna e heterogeneidade externa, sendo necessário, muitas vezes, retomar a codificação dos dados até que se consiga criar um mapa temático satisfatório ${ }^{12}$.

$\mathrm{Na}$ sequência, os temas são definidos e nomeados, ou seja, é identificada a essência do assunto.

E, por fim, a última fase, começa quando o conjunto dos temas já foram totalmente trabalhados, iniciando-se a análise final e a escrita do relatório ${ }^{12}$.

Para preservar o sigilo da identidade, os participantes foram representados, na transcrição, pela letra $\mathrm{D}$ de denunciado seguida de um número cardial indicativo da ordem de realização das entrevistas, da seguinte forma: D1, D2.... e D16.

O projeto foi aprovado pelo Comitê de Ética e Pesquisa com seres Humanos da Faculdade de Medicina de Marília, atendendo à resolução 510/2016, conforme Parecer $n^{\circ} 3.250 .567$, foram explicados os objetivos do estudo e dada a garantia do anonimato dos depoimentos, ocasião em que o Termo de Consentimento Livre e Esclarecido foi lido e assinado voluntariamente.

\section{RESULTADOS}

Foram entrevistadas 16 pessoas denunciadas por agressão a idosos. No processo de coleta de dados sete denunciados não aceitaram participar da entrevista e a outros treze não foi possível o contato, uma vez que muitos deles não atendiam ao telefone, estavam em encarceramento ou internação.

Quanto aos dados sociodemográficos constatouse que a idade dos denunciados variava de 38 a 86 anos, sendo que metade desses também são idosos. O sexo masculino foi predominante, sendo 12 (75\%) deles com escolaridade que vai desde o primário incompleto até àqueles que possuem nível superior completo. Dos denunciados, 11 (68,75\%) residem com o idoso, sendo a metade das ocorrências cometida pelo companheiro(a). A maioria relata não depender financeiramente e seis $(37,5 \%)$ cuidam do idoso. Observa-se, ainda, que 10 (62,5\%) dos denunciados faz uso abusivo de álcool e/ou drogas ilícitas ou tem algum transtorno mental, seja decorrente do uso de drogas ou não. Quanto ao tipo de violência acometida, observou-se que sete foram violência física, três verbal, duas psicológica e quatro negligência. A análise dos dados levou à definição de cinco temáticas finais e suas respectivas subtemáticas, segue o quadro 1 : 
Quadro 1. Distribuição dos temas e subtemas finais. Marília, SP. 2021

\begin{tabular}{|l|l|}
\hline Temas & Subtemas \\
\hline $\begin{array}{l}\text { Defendendo-se da acusação de } \\
\text { agressão }\end{array}$ & $\begin{array}{l}\text { Nega a acusação de agressão } \\
\text { Justifica a motivação da violência } \\
\text { Minimiza a situação de violência }\end{array}$ \\
\hline Dependência mútua & $\begin{array}{l}\text { Dependência financeira } \\
\text { Dependência de cuidados }\end{array}$ \\
\hline $\begin{array}{l}\text { Atribui a ocorrência ao } \\
\text { comportamento do idoso }\end{array}$ & $\begin{array}{l}\text { Xingamento } \\
\text { Invenção de fatos } \\
\text { Falta de compreensão do que é dito } \\
\text { História de convivência com a agressão }\end{array}$ \\
\hline $\begin{array}{l}\text { Reconhece suas necessidades e } \\
\text { busca soluções }\end{array}$ & $\begin{array}{l}\text { Agressão ocorreu por estar sob efeito de drogas psicoativas } \\
\text { Busca de tratamento para evitar agressão } \\
\text { Compara o cuidado do idoso a uma prisão }\end{array}$ \\
\hline $\begin{array}{l}\text { Sofrendo as consequências da } \\
\text { agressão. }\end{array}$ & $\begin{array}{l}\text { Auto negligência do denunciado } \\
\text { Desejando apagar a situação } \\
\text { Sentindo-se agredido emocionalmente } \\
\text { Dificuldade para lidar com a situação }\end{array}$ \\
\hline
\end{tabular}

Fonte: Elaboração própria

\section{Defendendo-se da acusação de agressão}

Ao serem entrevistados, os denunciados se defendiam da agressão cometida, por meio de justificativas, negação e minimização do fato ocorrido. Alegaram que estavam sob efeitos de drogas e que não tinham consciência do que estava acontecendo. A agressão física é negada, mesmo reconhecendo que estava sentindo raiva e que tenha pego no braço da vítima, existindo ainda a dificuldade em reconhecer tipos de agressões diferentes desta. Além das questões já mencionadas, o fato de nunca ter provocado agressão também parece dar ao agressor a sensação de não ter cometido o ato, pois alega que a lesão ocorreu por acidente próprio da vítima. Seguem abaixo alguns relatos:

"Brigamos verbalmente porque eu pedia dinheiro para comprar droga [...] Aconteceu que eu estava "chapado" e não sabia direito o que estava fazendo[...]Estava sem tratamento, agora eu aderi ao tratamento" (D1).

“[...]tem hora que é o seguinte, eu sinto raiva, mas não é que é raiva assim de agredir ninguém porque eu nunca a agredi. Se ela falou aqui no papel que eu a agredi, nunca agredi” (D2).
"Como é que alguém que me conhece[...] tem coragem de pegar um fato do dia-a-dia, ir na delegacia para me denunciar como agressor? Eu nunca encostei, eu nunca dei um beliscão em minha mãe[...]” (D7)

"Ela nem chegou a cair, ela fez assim, falseou o pé, quase caiu, mas deu a torçãozinha no pé, mas por ela sozinha! Ela se exaltou e quando ela mesma se exaltou, então ela deu aquele passo em falso" (D13).

"Foi uma bobeira, eu tinha mesmo um revólver dentro do carro[...]aí ela deu parte de mim, só que eu tinha dado um tiro um dia antes de noite, pra cima[...].eu me sinto numa raiva tremenda! Porque eu nunca, depois de 35 anos, eu fui parar na detenção. Só que nessa parte de agressão nunca teve!" (D14).

\section{Dependência mútua}

Nas entrevistas foi possível observar que há entre agredido e denunciado uma dependência mutua. Por um lado, o denunciado necessita do apoio financeiro da pessoa idosa e, por outro lado, a pessoa idosa depende de seus cuidados. Incluem-se também 
aqueles que alegam que não podem trabalhar pois precisam prestar os cuidados. Constata-se assim, que se trata de uma relação que irá se perpetuar conforme revelado a seguir:

"[...] ela depende de mim por causa da doença[...]. Ajudo em tudo [...] eu limpo a casa, eu faço almoço, tem vez que ela faz almoço. Eu a levo no médico[...] eu dependo mais dela do que ela de mim porque o dinheiro vai na mão dela. Como eu não posso trabalhar por causa dela, porque eu tenho que cuidar dela, então eu estou na mão dela (D2)”.

"Foi difícil porque, assim, eu trabalho e tive que parar meu serviço para ajudar cuidar (D3)".

\section{Atribui a ocorrência ao comportamento do idoso}

Os entrevistados alegam que a agressão ocorreu devido ao comportamento agressivo da pessoa idosa que realiza agressões verbais, por meio de xingamentos e invenção de fatos que não foram praticados por ele. Além disso, afirmam que a pessoa idosa não tem uma compreensão daquilo que é dito de fato, fazendo, assim, a sua própria interpretação. Há relatos de vivências importantes de agressão por alguns entrevistados que também já estiveram no papel de vítimas e agora parecem reproduzir essas vivências como agressor, segue os relatos:

"Ela me xinga de desgraçado, demônio, de tudo ela me xinga, ela não tem medo! o problema dela é a cabeça, ela inventa as coisas[...]” (D2).

"Ela é problemática, no sentido que é perturbada. Você fala uma coisa e ela interpreta de outra maneira[...]" (D4).

"Ele fica violento mesmo! Então a minha defesa é morder. Então eu carquei o dente bem em cima do peito dele, ele tem a marca até hoje!” (D10).

"Eu sou criado neste ninho, o que eu vou aprender? Não diz que o pai é o espelho do filho? Eu vou aprender isso aí [...]já tive que separar briga do meu pai, que meu pai bebia, agredia minha mãe[...] Ele deu 32 facadas no meu irmão[...]" (D12).

"Aí nós discutimos seriamente! Vou falar a verdade, se ela puder bater, ela bate. Minha mãe é osso duro, e eu a puxei! Por isso que eu e ela não dá certo, porque se eu for discutir com a pessoa e a pessoa começar a tirar, tipo, gracinha de mim, eu já não aguento. Eu sou um cara ignorante!” (D14).

\section{Reconhece suas necessidades e busca soluções}

O denunciado reconhece as suas fragilidades no desempenho desse papel, especialmente quando no papel de cuidador. A sobrecarga de cuidar do idoso parece constituir em uma tarefa penosa tanto física como emocionalmente, especialmente para aqueles que mostram não ter muitos recursos para tal, mesmo desejando cuidar e ficar ao lado do idoso. Ocorre também de apresentar algum transtorno mental ou emocional ou de fazer uso abusivo de bebida alcoólica, sendo que, em alguns casos, eles buscam soluções por meio de tratamento na tentativa de evitar que a agressão se repita.

"Então nós ficamos presos aí durante esses 16 anos e ninguém sabe até quando vai essa prisão.” (D3)

"Tudo que eu poder fazer com ela, eu faço por ela, coitadinha... Eu me casei com ela não foi para poder largar ela, entendeu? Não tem um ditado que fala assim "quem come a carne, rói o osso"? Assim mesmo sou eu. Eu casei com ela para ficar até o fim, entende?” (D2)

"Eu estou fazendo acompanhamento, estou tomando medicação. Tem hora que eu não tenho fôlego para mim, eu não tenho um momento meu. Eu entendo que eu tenho alguma descompensação psicológica, devido a tudo isso que eu já vivenciei e eu me sinto assim, eu tenho que trabalhar com isso, mas é calada e surdinha[...]” (D4).

"Mas, assim, eu sei meu limite. Eu acho que eu sei, não é? Mas bêbado nunca sabe o limite, não é?” (D12).

“Juntou depressão, a crise nervosa..." (D8).

\section{Sofrendo as consequências da agressão}

As situações de autonegligência e de sofrimento emocional, permeiam as situações de violência. Os denunciados tanto expressaram o fato de não tratarem doenças clínicas e mentais adequadamente, 
como deixaram de se alimentar adequadamente após a denúncia e, com isso, perdendo peso. Alegam ainda o desejo de apagar a situação, que estão se sentido agredidos emocionalmente ou que não sabem lidar com o que está ocorrendo.

“Então, eu tenho pressão alta, mas super alta! Já faz quase 2 anos que eu não tomo nada, suspendi tudo!" (D5).

"[...] eu gostaria que fosse passada uma borracha, eu queria seguir a minha vida e que ela segue a dela". (D4).

"Olha, eu vou dizer para você[...] Me senti, assim, tão agredido emocionalmente porquê[...] o fato de achar que eu possa ter feito já me incomoda!” (E7).

"Estou péssima, psicologicamente abalada. Eu não estou conseguindo lidar com essa situação, porque, assim, em toda a minha vida, 48 anos eu nunca tive problema com a justiça[...]" (D15).

\section{DISCUSSÃO}

A realização do presente estudo, o qual buscou interpretar as vivências dos denunciados de agressão à pessoa idosa, constituiu-se em um grande desafio, visto que as condições dos denunciados são complexas e adversas, uma vez que há a internação, cárcere ou falta de lucidez dos entrevistados; este último por conta do uso abuso de drogas lícitas e ilícitas ou pela presença de transtorno mental.

Além disso, perpassa pela dificuldade de investigação do fenômento, o fato de ser um tema silenciado e revestido de tabus ${ }^{7}$, porque na maioria das vezes ocorre no seio familiar, a qual é vista como um espaço de proteção e cuidado, e, apesar do sigilo das informações e não interferência processual do caso, os entrevistados mantém-se receosos e com dificuldade de tratar a temática.

Dados do presente estudo corroboram com a literatura demonstrando que os principais agressores são do sexo masculino e fazem uso abusivo de álcool e drogas ilícitas. Ainda, são características em comum: comportamento hostil e agressivo, desemprego, problemas financeiros, coabitação, história de relacionamento difícil, estresse decorrente do cuidado do idoso e a possível transmissão intergeracional de condutas violentas ${ }^{15,16}$. As vítimas do sexo feminino sofrem mais agressões por cônjuges e, do sexo masculino, por filhos. As principais características dos idosos que sofrem agressão são: dependência física e/ou intelectual, demência, depressão ou comportamento agressivo e desafiante.

A violência contra o idoso perpretada por familiares no próprio domić́lio ganha relevância ao se considerar que a legislação nacional, por meio da Constituição Federal e do Estatuto do idoso, conferem ao mesmo a proteçao integral, assegurando oportunidades e facilidades para a preservação da saúde física e mental, bem como seu aperfeiçoamento moral, intelectual, espiritual e social, em condições de liberdade e dignidade, haja vista que tais garantias devem ser proporcionadas pelo estado e pela família ${ }^{17,18}$.

Destaca-se que nas últimas décadas a família vem passando por modificações, incluindo a sua fragmentação, com as vivências menos tradicionais da conjugalidade, redução da natalidade e a redução do tempo disponível para os cuidados, visto que tanto as mulheres como os homens assumem extensas atividades laborais ${ }^{19,20}$

Quanto ao presente estudo, deve-se destacar que metade dos participantes são idosos e também companheiros ${ }^{18,19}$. Portanto, embora viver com o companheiro represente um fator de proteção contra abuso físico ou financeiro ${ }^{21}$, a injustiça quanto à divisão de trabalhos domésticos, investimento excessivo em questões pessoais, influências de fatores ambientais e questões de tomada de decisões importantes ao contexto do cônjuge de forma unilateral ${ }^{22}$ propiciam à violência.

$\mathrm{Na}$ análise das entrevistas com os agressores, observa-se um padrão de falas revestidos de mecanismos de defesa, incluindo essencialmente a negação da agressão cometida e a racionalização. A negação trata-se da recusa consciente em perceber fatos perturbadores e a racionalização compreende a criaçao de desculpas falsas para jutificar o comportamento ${ }^{23}$.

Isso decorre do fato de que ao aceitar ter agredido o idoso, o agressor se defronta com dano emocional intolerável e com o reconhecimento de que cometeu um ato falho. Trata-se de uma condição que precisa 
ser considerada e abordada por profissionais de saúde, para que o denunciado consiga entender os fatos, considerando que a recusa consciente no enfrentamento de fatos perturbadores dificulta ao indivíduo lidar com os desafios e estabelecer estratégias adequadas no relacionamento ${ }^{24}$. Assim, quando os entrevistados admitem que perpetraram a violência contra a pessoa idosa, eles também reconheceram que necessitavam de ajuda para melhorar o comportamento agressivo ${ }^{25}$.

O papel de cuidador, por sua vez, também representa um grande desafio devido à sobrecarga que o mesmo requer. Um estudo identificou que um terço deles apresentou sobrecarga de cuidado, o que foi associado à idade, à disfunção familiar e à prestação de cuidado contínuo, visto que na maioria das vezes o cuidado recai sobre uma única pessoa ${ }^{25}$.

Caminhando na perspectiva de compreender a violência, é perceptível que ela é considerada uma condição multifatorial, que muitas vezes tem sua origem na infância, pela ineficácia na conduta dos pais ou responsáveis em colocar limites ao mau comportamento. Além disso, identificam-se características em comum entre vítima e agressor, sendo a vítima quem molda o agressor, sendo assim, o abuso, ocorrido na infância, permeia o funcionalismo psicológico na idade adulta, refletindo nas relações familiares posteriores ${ }^{26,27}$.

Tem-se, ainda que a violência é uma questão culturalmente determinada e, embora tenha uma relação direta com a intencionalidade do ato, ou seja, considera-se como violência quando o ato é intencional, pode, em determinadas crenças e culturas, não ser considerada como tal ${ }^{28,29}$.

Observa-se ainda que os agressores manifestam sentimentos de auto punição quando informam que deixaram de tomar os medicamentos ou de se alimentarem adequadamente, sendo demonstrado por meio da autonegação do prazer e por penalidade auto-impostas $^{30,31}$.

A necessidade de uma abordagem adequada visando a resolução dos conflitos existentes entre agredido e denunciado ganha relevância ao se verificar que nessa relação há uma dependência mútua e que a mesma irá se perpetuar após a ocorrência e as medidas judiciais cabíveis, pois-na maioria dos casos existe uma dependencia financeira ou de cuidados entre ambos os envolvidos nessa relação.

Por fim, mesmo frente às limitações do estudo por se tratar de um assunto que causa constrangimento e que, portanto, os participantes podem omitir ou distorcer as informações, além de se utilizar de entrevistas com apenas uma pequena parcela dos denunciados por agressão, em decorrência das dificuldades em fazer as entrevistas, o presente estudo traz reflexões importantes, haja vista que, tanto agredido como o denunciado necessitam de cuidados específicos dos profissionais de saúde.

\section{CONCLUSÃO}

Este estudo evidenciou que dar voz ao denunciado de agressão à pessoa idosa é deparar-se com situações que envolvem necessidades socioeconômicas e de saúde, em um contexto de relações de difícil manejo, pois na maioria dos casos o denunciado é um integrante da família e esse convívio irá se perpetuar pela dependência mútua entre eles.

Os denunciados buscam defender-se da agressão e, nesta perspectiva, negam, justificam e minimizam o ato cometido. Observa-se também a existência de dependência mútua, seja financeira ou de cuidados, o que muitas vezes dificulta ou até impede que a convivência seja interrompida. O comportamento agressivo, por meio de xingamentos e histórias de convivência com agressões perpetuadas pelo idoso, além da árdua tarefa de cuidar do idoso, o uso abusivo de álcool e de drogas ilícitas foram fatores que contribuíram para as agressões. Os entrevistados expressam sentimento de culpa e arrependimento pela agressão perpetrada, reconhecem as suas necessidades e buscam apoio para o enfrentamento da situação.

Nas situações de agressão é preciso que haja uma escuta ampliada. Para isso, é preciso dar voz para as necessidades tanto da pessoa idosa como do denunciado, para que seja possível caminhar de forma construtiva na resolução do conflito. Recomenda-se, portanto, o apoio de uma equipe de saúde multidisciplinar em um trabalho articulado com outros setores.

Editado por: Tamires Carneiro de Oliveira Mendes 


\section{REFERÊNCIAS}

1. Brasil. Secretaria de Direitos Humanos da Presidência da República. Manual de enfrentamento à violência contra a pessoa idosa: É possível prevenir. É necessário superar [Internet]. 2013 [acesso em 01 dez. 2018]. Disponível em: http:// www.cedi.pr.gov.br/arquivos/File/CEDI/ ManualViolenciaIdosogovfedweb.pdf.

2. Brasil. (Constituição, 1988). Constituição da República Federativa do Brasil. Brasília, DF: Senado Federal; 1988.

3. Pina SCT, Coelho APF, Torres JC, Teixeira AB. O papel da família e do Estado na proteção do idoso. Ciênc ET Praxis. 2017;9(18):35-40. Disponível em: http://revista.uemg.br/index.php/praxys/article/ view/2532/1495.

4. Carrara BS, Espírito Santo PMF. Old age institutionalized in postmodern times: the identity in parallel universe? Rev Enferm UFPE on line. 2016;10(5):1672-89. Disponível em: https://periodicos. ufpe.br/revistas/revistaenfermagem/article/ view/13542/1631.

5. Souza A, Pelegrini TS, Ribeiro JHM, Pereira DS, Mendes MA. Concept of family insufficiency in the aged: critical literature analysis. Rev Bras Enferm. 2015;68(6):864-73. Disponível em: http://dx.doi. org/10.1590/0034-7167.2015680625i .

6. Santana IO, Vasconcelos D, Coutinho MPL. Prevalência da violência contra o idoso no Brasil: revisão analítica. Arq Bras Psicol. 2016;68(1):12639. Disponível em: http://pepsic.bvsalud.org/ scielo.php?script $=$ sci_arttext\&pid=S180952672016000100011\&lng=pt .

7. Castro VC, Rissardo LK, Carreira L. Violence against the brazilian elderlies: an analysis of hospitalizations. Rev Bras Enferm. 2018;71(2):777-85. Disponível em: https://doi.org/10.1590/0034-7167-2017-0139.

8. Garbin CAS, Joaquim RC, Rovida TAS, Garbin AJI. Elderly victims of abuse: a five years document analysis. Rev Bras Geriatr Gerontol. 2016;19(1):8794. Disponível em: http://dx.doi.org/10.1590/18099823.2016.15037.

9. Lachs MS, Pillemer KA. Elder abuse. N Engl J Med. 2015]; 373: 1947-56. Disponível em:http://doi. org/10.1056/NEJMra1404688

10. Brasil. Ministério da Saúde. VIVA: Vigilância de Violências e Acidentes: 2013 e 2014. Brasília, DF: MS; 2017 [acesso em 20 mar. 2018]. Disponível em: http:// bvsms.saude.gov.br/bvs/publicacoes/viva_vigilancia_ violencia_acidentes_2013_2014.pdf.
11. Rodrigues RAP, Monteiro EA, dos Santos AMR, Pontes MLF, Fhon JRS, Bolina AF, et al. Older adults abuse in three Brazilian cities. Rev Bras Enferm. 2017;70(4):783-91. Disponível em: https://doi. org/10.1590/0034-7167-2017-0114.

12. Braun V, Clarke V. Using thematic analysis in psychology. Qual Res Psychol. 2006;3(2):77-101. Disponível em: http://dx.doi.org/10.1191/147808870 6qp063oa.

13. Instituto Brasileiro de Geografia e Estatística. Censos demográficos: censo demográfico 2010 [Internet]. Marília: IBGE; [2011] [acesso 06 fev. 2019]. Disponível em:https://ww2.ibge.gov.br/home/ estatistica/populacao/censo2010/default.shtm.

14. Minayo MCS. Amostragem e saturação em pesquisa qualitativa: consensus e controvérsias. Rev Pesq Qualitat. 2017;5(7):1-12. Disponível em: https://www.researchgate.net/ publication/315756131_AMOSTRAGEM_E_ SATURACAO_EM_PESQUISA_QUALITATIVA_ CONSENSOS_E_CONTROVERSIAS_ SAMPLING_AND_SATURATION_IN_ QUALITATIVE_RESEARCH_CONSENSUSES_ AND_CONTROVERSIES

15. Almeida FSA, dos Santos CL, Vieira DN. Abuso de idosos e o papel dos profissionais de saúde. Rev Port Med Geral Fam. 2019;36:24-34. Disponível em: http:// www.scielo.mec.pt/pdf/rpmgf/v36n1/v36n1a04.pdf.

16. de Matos NM, Albernaz EO, de SouSa BB, Braz MC, do Vale MS, Pinheiro WA. Profile of aggressors of older adults receiving care at a geriatrics and gerontology reference center in the Distrito Federal (Federal District), Brazil. Rev Bras Geriatr Gerontol. 2019;22(5):e190095. Disponível em: https://doi. org/10.1590/1981-22562019022.190095.

17. Veras R, Oliveira M. Care pathway for the elderly: detailing the model. Rev Bras Geriatr Gerontol. 2016;19(6):887-905. Disponível em: http://dx.doi. org/10.1590/1981-22562016019.160205.

18. Brasil. Secretaria Especial dos Direitos Humanos. Estatuto do idoso: lei federal no 10.741 , de 01 de outubro de 2003. Brasília, DF: SEDH; 2004.

19. Pina SCT, Coelho APF, Torres JC, Teixeira AB. O papel da família e do estado na proteção ao idoso. Ciência et Praxis. 2016;9(18):35-38.

20. Aguiar CSA, Menezes TMO, Camargo CL. Arranjos familiares com pessoas idosas: fatores contributivos. Av Enferm. 2018;36(3):292-301. Disponível em: http://www.scielo.org.co/pdf/aven/v36n3/01214500-aven-36-03-292.pdf . 
21. Eslami B, Viitasara E, Macassa G, Melchiorre MG, Lindert J, Stankunas M, et al.The prevalence of lifetime abuse among older adults in seven European countries. Int J Public Health. 2016;61(8):891-901. Disponível em: https://europepmc.org/article/med/27083450.

22. Faulkner RA, Davey M, Davey A. Gender-related predictors of change in marital satisfaction and marital conflict. Am J Fam Ther. 2007;33:61-83.

23. Weiten W. Introdução à psicologia: temas e variações. 4. ed. São Paulo: Pioneira; 2002.

24. Muniz PR, Almeida JFC, Teixeira KMS, Vasconcelos EAR. Análise dos mecanismos de defesa do ego utilizados pelos etilistas e o impacto do vício no meio social. DRIUFT. 2021;7(4):124-37. Disponível em: https://sistemas.uft.edu.br/periodicos/index.php/ desafios/article/view/9245

25. Nunes DP, de Brito TRP, Duarte YAO, Lebrão ML. Cuidadores de idosos e tensão excessiva associada ao cuidado: evidências do Estudo SABE. Rev Bras Epidemiol. 2018;21(Supl 2):e180020. Disponível em: http://www.scielo.br/scielo.php?script $=$ sci_ arttext\&pid=S1415-790X2018000300417\&lng=en.

26. Nóbrega Jr. JMP. Teorias do crime e da violência: uma revisão da Literatura. BIB. 2015;77:69-89. Disponível em: https://www.anpocs.com/index.php/bib-pt/ bib-77/9984-teorias-do-crime-e-da-violencia-umarevisao-da-literatura/file
27. Reisig MD, Holtfreter K. The victim-offender overlap in late adulthood. J Elder Abuse Negl. 2018;30(2):14466. Disponível em: https://doi.org/10.1080/08946566 .2018.1426512.

28. da Costa CB, Mosmann CP. Estratégias de resolução dos conflitos conjugais: percepções de um grupo focal. Psico. 2015;46(4):472-82. Disponível em: http:// dx.doi.org/10.15448/1980-8623.2015.4.20606.

29. Dahlberg LL, Krug EG. Violência: um problema global de saúde pública. Ciênc Saúde Colet. 2006;11(Supl):1163-78. Disponível em: https://doi. org/10.1590/S1413-81232006000500007.

30. Julle-Danière E, Whitehouse J, Mielke A, Vrij A, Gustafsson E, Micheletta J, et al. Are there non-verbal signals of guilt? PLoS One. 2020;15(4):e0231756 Disponível em: https://doi.org/10.1371/journal. pone. 0231756 .

31. Vaish A. The prosocial functions of early social emotions: the case of guilt. Curr Opin Psychol. 2018;20:25-9. Disponível em: http://doi.org/10.1016/j. copsyc.2017.08.008. 